\title{
Victimology from clinical psychology perspective: psychological assessment of victims and professionals working with victims
}

\author{
Tuğba Yılmaz ${ }^{1}$ (D) \\ Accepted: 28 January 2021 / Published online: 5 February 2021 \\ (C) The Author(s), under exclusive licence to Springer Science+Business Media, LLC part of Springer Nature 2021
}

\begin{abstract}
Victimology concerns victims of various traumas from accidents, disasters, assaults to wars. Survivors of trauma are also an area in clinical psychology since it is interested in the assessment and diagnosis of psychopathology and psychotherapy. Stress and mental health are intertwined; increased stress results in difficulties in feeling, thinking and behaving. The stress symptoms are an intrusion, avoidance, negative cognitions and mood, and arousal and reactivity. A trauma survivor might develop post-traumatic stress disorder. Healing trauma is so comprehensive that many professionals work from different aspects. From attorneys to mental health workers, many professionals deal with the aftereffects of trauma. Engaging with details of the trauma endangers not only the victims but also the professionals working with the victims. These professionals end up having psychological effects such as secondary trauma, vicarious trauma, compassion fatigue, countertransference and occupational burnout. Trauma has serious effects on its victims but not all effects are negative and paralyzing. Trauma victims might change their priorities in a way that they report more personal control over their life. This phenomenon is called posttraumatic growth. The paper aims to collaborate victimology with clinical psychology by highlighting psychopathology and psychological assessment.
\end{abstract}

Keywords Trauma $\cdot$ Posttraumatic stress disorder $\cdot$ Vicarious trauma $\cdot$ Secondary trauma $\cdot$ Psychotherapy $\cdot$ Victim

Karmen (2012) postulated that victims are people who are affected negatively such as having an injury or a hardship because of an illegal action of people or group of people. Victimology is the name of the scientific study of victims and the victimization process (Turvey, 2014). Van Dijk (1999) suggested that victimology has variety in itself so that there are penal victimology and general victimology. This diversification depends on the idea that penal (interactionist) victimology heavily depends on criminal law and conceptualizes the victim in criminological and legal terms. On the other hand, general victimology defines the victim in a much broader manner than the other. In general victimology, victims are thought as people who had harm by different types of trauma such as accidents, disasters, assaults and wars (Van Dijk, 1999). This study aims to provide knowledge from clinical psychology in evaluating general victimology which is an interdisciplinary area involving law, forensic psychology, sociology, economics and so on.

Tuğba Yilmaz

tugba.yilmaz.psy@gmail.com

1 İzmir Bakırçay University, İzmir, Turkey
Clinical psychology is a branch of psychology that concerns psychological assessment, and diagnosis and treatment of psychological disorders and behavioral problems (Plante, 2005). Victims are individuals who are negatively affected by an event such as a criminal act, disaster or accident. Being exposed to such a devastating event, individuals might be affected physically and/or psychologically. They might be suffering from some emotional, cognitive and behavioral problems. By adopting the biopsychosocial model (Engel, 1977) the effects a victim might experience should be conceptualized from biological, psychological and social aspects. This study tries to understand how a victim gets seriously affected by a negative event from a psychopathological viewpoint. The psychological treatment of psychopathologies after an adverse event is explained in the next section. After this, a different viewpoint will be highlighted by altering the focus point from victims to people who work with victims. Professionals whose job is to closely work with victims are also affected by the adverse events (Y1lmaz \& Karakuş, 2019). Following the discussion of secondary trauma, vicarious trauma, compassion fatigue and occupational burnout that professionals might feel, coping ways with these feelings are explained in the light of current literature. 
The author also wants to point out the importance of working with victims by reviewing the critical points from the literature. Many professionals including clinical psychologists work with victims in the rehabilitation of aftereffects. The psychological effects of being a victim seem to affect professionals working with victims, too (Y1lmaz \& Karakuş, 2019). In the first part of this study, the author highlighted the psychological aftereffects of victims have after a devastating and/ or criminal event. Psychological symptoms and disorders are discussed in terms of acute stress disorder, post-traumatic stress disorder, dissociative disorders, depressive disorders, and substance use disorders. The groups of these psychopathologies are explained by taking the Diagnostic and Statistical Manual of Mental Disorders, fifth edition (DSM5; American Psychological Association [APA, 2013) as a reference. A brief history of effects of victims in psychopathology, especially the effects of WWI and WWII and the rise of applied psychology (Schultz \& Schultz, 2008) was described. Effects of victimization in DSM history were discussed by considering how victim-specific psychological diagnoses changed over time (Y1lmaz, 2019a). Treatment of psychopathologies were detailed throughout the study. The author suggested books, movies and series about victimization to support the discussion.

\section{Stress and Mental Health}

Stress is a kind of condition in which people feel challenged beyond their coping abilities (Shalev, 2009). Stress might have detrimental effects on physical health and psychological health. The negative effects of stress are acknowledged by the function of the HPA axis where the hypothalamus, pituitary gland, and adrenal glands interact and prepare an organism to perform a stress response such as fight, freeze or flight (Bracha, 2004).

The effects of stress are well- acknowledged in the development of psychological diagnoses. As a result, Diagnostic and Statistical Manual of Mental Disorders fifth edition (DSM-5), the well-known handbook of psychological disorders that was published by American Psychiatric Association (APA) included a new diagnostic category named trauma and stress related disorders (APA, 2013). Under this diagnostic category, there are adjustment disorder, acute stress disorder and post-traumatic stress disorder (PTSD; APA, 2013). Formerly in DSM-IV-TR, acute stress disorders and PTSD are grouped under anxiety disorders category; whereas, adjustment disorders were a separate diagnostic category (Y1lmaz, 2019a). The reason lying behind the change of the diagnostic category of these disorders is the fact that major stressors are playing very crucial and central role in the development of them (Butcher, Mineka, \& Hooley, 2014).

\section{Psychological Disorders a Victim Might Develop}

Victims are individuals who are involved in a criminal activity and affected psychologically and physically (Van Dijk, 1999). The psychological effects of being a victim due to a criminal event have been investigated in clinical psychology literature, especially under trauma-related disorders. To exemplify, sexual and physical assault victims (Kimerling \& Calhoun, 1994; Resick \& Schnicke, 1992), rape victims (Foa, Rothbaum, Riggs, \& Murdock, 1991; Nishith, Resick, \& Griffin, 2002; Resick, Nishith, Weaver, Astin, \& Feuer, 2002), victims of war and torture (Hensel-Dittmann et al., 2011), victims of traumatic head injury (Benedict, 1989), motor vehicle accident victims (Blanchard et al., 1995), traffic accident victims (Frommberger et al., 1999); cyberbullying victims (Campfield, 2008), disaster victims (Rubonis \& Bickman, 1991; Rüstemli \& Karanci, 1999; Sumer, Karanci, Berument, \& Gunes, 2005) are the groups of people of whom psychologists evaluate, understand and treat. One important point to highlight in reviewing the literature is to realize that the number of people who report they had been victimized is lower than that of the actual people who had been victimized. Kilpatrick, Saunders, Veronen, Best, and Von (1987) stated that approximately half of the people who were victimized did not report the police. The highest reporting rate is for burglary whereas sexual assault had the lowest reporting rate. One in third of the victimized people stated that they had developed post-traumatic stress disorder (PTSD) after the criminal event (Kilpatrick et al., 1987). These results suggest that there are victims who are unrecognized and unreported but these people continue their lives despite the serious adversity they had experienced. Research show that the effects of a trauma is inherited and transferred to next generation family members who are in fact not related to it (Öztürk, 2020; Wolynn, 2017). Moreover, research also indicate that the risk of being traumatized is increased if there is a prior personal experience with a traumatic event (Altınay \& Arat, 2007; Zara-Page \& İnce, 2008). Considering these important results, unrecognized and unreported victims who are traumatized are not just a concern for clinical psychology, psychiatry or victimology; they are also concern for public health.

Victimization is a distressing event and victims might have psychological problems after the event or during the event since some criminal activities are not one-time events. Wellknown psychological outcome of being a victim is posttraumatic stress disorder (PTSD; Mason \& Lodrick, 2013; Turvey, 2014). Compared to PTSD, having similar symptoms for a shorter duration deserves for acute stress disorder (ASD; APA, 2013). ASD and PTSD are psychopathologies acknowledged by DSM as well as adjustment disorders. PTSD might be comorbid with anxiety disorders, substance abuse disorders, dissociative disorders and depressive disorders. Some 
victims who developed PTSD might engage in self-harmful behaviors to alleviate the negative feelings due to the traumatic event (Mason \& Lodrick, 2013). Turvey (2014) reviewed the trauma victim literature in the forensic area and concluded that although not recognized by APA in DSM, there are some victim specific syndromes in the literature. These syndromes are the battered woman syndrome (Walker, 1984), rape trauma syndrome (Burgess \& Holmstrom, 1974), and stalking trauma syndrome (Colins \& Wilkas, 2001).

In understanding symptomatology PTSD, DSM-5 criteria grouped symptoms under four categories, namely intrusion, avoidance, negative cognitions and mood, and arousal and reactivity. Intrusion refers to re-experiencing of the traumatic events in various ways such as nightmares, intrusive images and showing physiological reactivity to reminders of the trauma. Intrusion might lead accessing traumatic episodic memory, which might cause victim to experience autonomic nervous system arousal, i.e., physiological reactivity (Mason \& Lodrick, 2013). This is particularly important for police interview and courtroom testimonies with which victims recall traumatic event and might re-experience the traumatic event (Mason \& Lodrick, 2013). The second group of symptoms is avoidance, which includes symptoms related to victims' efforts to avoid reminders, feelings and thoughts of the trauma. The third group of symptoms is negative cognitions and mood. This group includes victim's blaming him/herself or others and other negative emotional states like shame, guilt, and anger. Feelings of detachment and estrangement from others, and inability to have positive emotions is also included in this group of symptoms. The last group of symptoms is called changes in arousal and reactivity. Sleep disturbance, hypervigilance, exaggerated startle response, and reckless and self-destructive behavior might be experienced in traumatized victims under this group of symptoms. The duration of PTSD must be more than one month. There are two sub-types of PTSD. The first is PTSD with dissociative symptoms such as depersonalization and derealization. The second is PTSD with delayed expression. In this sub-type, victims might now show the full-blown symptoms of PTSD until at least 6 months after the traumatic event. In this instance, the onset and the beginning of some symptoms might begin immediately.

Turvey (2014) shed light on important issues in terms of psychological assessment of victims. He suggested that victims are traumatized and victimized twice, one by the offender and the second by the criminal justice system. This is critically important since the adverse effects are repeated for living victims. Second, Turvey (2014) indicated that violent events rarely happen just one victim. Generally, there are more than one victim involved in the actual assault. Moreover, there are collateral victims who are spouses, friends and children of the assaulted victim. These individuals are also negatively affected by the adverse event. Even the diagnostic category of PTSD acknowledges that collateral victims could be diagnosed with PTSD as long as they show symptoms. Collateral victims might witness the assault in person, or they might learn a brutal or violent crime might happen to someone very close to them, or else they might experience extreme exposure to aversive details of the traumatic event (Butcher et al., 2014). Investigators, prosecutors, and defense attorneys should take these facts into consideration. As Mason and Lodrick (2013) postulated heightened in the interview of victims, ANS response might stimulate archaic structures of the brain which controls survival of the organism and the victims might feel as if the real danger is close to them, which might lead them to become more cooperative or compliant. This might cause inconsistencies between the accounts they have given in processing their complaints through the criminal justice system.

Acute stress disorder (ASD) is very similar to PTSD in terms of symptomatology. Intrusion symptoms, negative mood, dissociative symptoms, arousal, and avoidance symptoms include 14 different symptoms. The difference between ASD and PTSD is about the duration of the symptoms as the brief history of these disorders can tell. For ASD, symptoms are expected to begin after the trauma and to last at least 3 days and at most 1 month (APA, 2013). If the duration of the symptoms exceeds 1-month threshold, the diagnosis is altered to PTSD (Butcher et al., 2014). The function of ASD diagnose is to detect a victim who need immediate professional help and ensure him/her with evidence based psychological treatment.

Adjustment disorders (ADs) are yet another diagnosis that a victim might develop. In terms of symptomatology, ADs do not have a long list of symptoms. This diagnosis can be counted as a sign of an individual's difficulty in returning to their routines after a stressor strike and ended. The individual has clinically high degree of stress in adjusting to their normal life. DSM-5 says that an individual has marked stress and/or impairment in important areas of functioning within 3 months of the onset of the stressor and once the stressor ended the symptoms do not last more than 6 months (APA, 2013). The connection between ADs and victimization was studied. For example, Bachem and Maercker (2016) studied with burglary victims who developed Ads at clinical and subclinical level. They compared intervention group and wait-list group in terms of Ads symptoms. The psychotherapeutic intervention in this study was bibliotherapeutic self-help intervention, which as its name implies did not have any therapists. Results yielded that was bibliotherapeutic self-help intervention worked well in terms of effectively treating symptoms of ADs (Lorenz, Bachem, \& Maercker, 2016). Similarly, Sirles, Smith, and Kusama (1989) reported that children victims of intrafamilial sexual abuse might have different diagnoses, one of which is ADs. Lönnqvist et al. (1995) analyzed all adolescent suicides in Finland between 1987 and 1988. They reported that $\mathrm{AD}$ diagnosis was observed only in male suicide 
victims. All these studies indicate the importance of diagnosing ADs in both living or deceased victims.

Not every people can meet the full criteria for PTSD, ASD or ADs after a specified trauma and DSM appreciates this case by suggesting "other-speficied trauma and stressor related disorder" as a diagnosis. In assigning this diagnosis, a clinician is expected to specify the reason. The specifiers of this diagnosis are "adjustment-like disorders with delayed onset of symptoms that occur more than 3 months after the stressor", "adjustment-like disorders with prolonged duration of more than 6 months without prolonged duration of stressor", "Ataque de nervios", "other cultural syndromes", and "persistent complex bereavement disorder". In cases for whom the trauma is not specified, there is another option. This option is "unspecified trauma and stressor related disorder". A clinical might not have clear information in assigning a specific diagnosis in trauma and stressor related disorders diagnosis group and instead can assign "unspecified trauma and stressor related disorder". This might happen in emergency settings and in crises (APA, 2013).

PTSD, ASD, ADs and other- or unspecified trauma and stressor related disorder are official diagnoses which are presented in DSM-5. Nevertheless, the literature has more options in terms of diagnoses. Turvey (2014) pointed out battered woman syndrome (Walker, 1984), rape trauma syndrome (Burgess \& Holmstrom, 1974), and stalking trauma syndrome (Colins \& Wilkas, 2001) are trauma syndromes discussed in the literature. All three syndromes share a common point in alleging that they are a part or sub-type of PTSD. Although these syndromes have not been assigned in DSM-5; authors suggesting these syndromes are a part of DSM-5 (Turvey, 2014).

Battered woman syndrome was first coined by Walker (1984) after conducting a study in which she interviewed 435 women who were victims of domestic violence. In offering battered woman syndrome, Walker's aim is to explain why women chose to remain in a relationship in which she was experiencing violence. She formulated the cycle of violence in which learned helplessness is the reason why woman believe that they cannot change the ongoing relationship (Walker, 1984). the symptoms of battered woman syndrome are similar to PTSD. This syndrome is gender specific syndrome and actually was not supported by other studies other than those of Walker. Turvey (2014) points out that if a woman is facing physical violence and if a diagnosis is needed to be assigned; rather than thinking about PTSD as a first-line choice, the symptoms of the woman should be understood because other diagnoses might be plausible, too.

Rape trauma syndrome (RTS) was described for forcible rape or attempted forcible rape by Burgess and Holmstrom (1974) who interviewed 146 women victims of rape. They purported that there is an acute and long-term phase of RTS. In acute phase, which consists of immediate impact phase, victims are engaging in their emotions and might end up in two alternative responses: being expressive or guarded. Expressive victims unclose how they feel whereas guarded ones do not. The authors also acknowledge that a rape victim might change her emotional response from one another. Long term phase of RTS is reorganization when a victim realizes that her lifestyle is affected in different ways (Burgess \& Holmstrom, 1974). Although once accredited as a mental diagnosis of victims in courts, RTS was not an official diagnosis. Turvey (2014) criticizes both RTS and BTS on many common points. One is these syndromes are not validated by other researchers. Second, there is no follow-up validation. Third, there are no control groups comparing the affected group against. Fourth, the samples from which both BWS and RTS were described were preselected samples. The last one is these syndromes are gender-specific. Because of these reasons and many others, DSM never listed these syndromes as official diagnoses although accepted rape as a serious trauma and/or stressor for PTSD diagnosis.

Stalking trauma syndrome (STS; (Colins \& Wilkas, 2001) is yet another syndrome discussed in the literature regarding mental health of victims. First, stalkers are people who engage in repetitive acts to harass a victim. Stalking might happen in real or cyber lives. Turvey (2014) states that some stalkers might be delusional in inferring that the victim wants to form a relationship with them while most stalkers are people who are angry with the victim because of a break-up which in fact they deny. Colins and Wilkas (2001) stated that STS is different when compared to BWS and RTS. STS is not an outcome of one incident like rape, it is an ongoing stressor. Victims of STS experience traumatic symptoms for a while when stalking is in progress. Moreover, STS victims are in actual helplessness rather than learned helplessness occurred in BWS. The authors described crisis and anticipation phase of STS while recovery phase is absent due to continuous fear of next harassment (Colins \& Wilkas, 2001). The authors suggested that stalking causes hopelessness and helplessness in victims. Turvey (2014) highlights that these are symptoms of any crime victim. In other words, the symptoms are not differentiating the effect of stalking; they are actually too general symptoms that might be seen in any victim. He states that pathologizing normal reactions of victims might be the case in introduction of these syndromes. These syndromes should have divergent validity, each one of them should be differentiated from one another.

\section{Brief History of these Psychological Disorders}

How psychopathology begin to recognize trauma-related disorders is related to wars and their aftereffects. Applied psychology including clinical psychology developed after World War I and II (Schultz \& Schultz, 2008). After World War I, 
veterans return home suffering from combat. Shell shock and combat fatigue were the names of the syndromes for traumatized soldiers. After World War II, gross stress reaction was accepted as a diagnosis in the first edition of DSM. The second version of DSM excluded gross stress reaction diagnosis partly because this edition was prepared in a war-free era (Andreasen, 2004).

After Vietnam war, psychiatrists came to understand that veterans were not able to return to their lives prior to war (Butcher et al., 2014). First, DSM II task force suggested to include Post-Vietnam Syndrome in DSM, since psychiatrists relied on DSM II and unable to diagnose traumatized veterans. Then PTSD was added to DSM as a diagnosis as well as acute PTSD. Trauma was defined as a stressor which was outside the range of normal human experience (Andreasen, 2004; Butcher et al., 2014). Psychiatrists began to argue about the nature of the traumatic event and they broad the application of the diagnosis to other stressors such as childhood sexual abuse (Andreasen, 2004). DSM-III definition of PTSD relied on the qualities of the stressor; later version of the diagnosis in DSMIV-TR emphasized the emotional response of the victim (Shalev, 2009). Acute PTSD was dropped in DSM-III-R but it was named as acute stress disorder and accepted as a diagnosis in DSM-IV (Andreasen, 2004). In terms of PTSD, DSM-IV-TR suggested that in addition to the fact that the stressor should be outside the range of normal human experience, the response to the stressor should involve helplessness, horror or intense fear (Butcher et al., 2014). This change highlights the focus of the PTSD diagnosis, now the focus is on the experience of the victim rather than the quality of the stressor.

DSM-5 is the latest version of psychopathology and there are other changes in PTSD diagnosis. The changes are about the definition of the traumatic event, the diagnosis for children 6 years and younger. Exposure to traumatic event was detailed, as well. Traumatic event might happen to victim him/ herself or the victim might witness a traumatic event personally. Other way of exposure to a traumatic event is that a victim may learn that a violent or accidental event happened to some very close like a family member or a close friend. The exposure excludes experience of a traumatic event through electronic media. The requirement of emotional experience of the trauma in the form of helplessness, intense fear or horror removed. Diagnostic criteria were explained in a separate section for children who are 6 years of age or younger (APA, 2013; Y1lmaz, 2019a).

\section{Treatment of Post-Traumatic Stress Disorder}

Post-traumatic stress disorder is a common type of psychopathology that can be seen surviving victims. Many clinical psychologists are working on psychological treatment of PTSD.
There are many efficient and effective psychotherapies of PTSD.

Cognitive behavioral therapy (CBT) for PTSD is one of the important and successful methods in treatment of PTSD (Zayfert \& Becker, 2019). CBT is an eclectic form of psychotherapy in which cognitive models of psychotherapy and behavior analysis incorporate. According to CBT, psychopathologies lie PTSD are an outcome of dysfunctional thinking and they can be altered by new learning. Hence, as a response to a traumatic event people have some cognitions and behaviors, which compose PTSD and related difficulties. CBT aims to modify these cognitions and behaviors which are after-effects of trauma. Keane and Barlow (2002) states that sustaining factor for PTSD is avoidance symptoms. Surviving victims, for instance, might prefer staying away from crime scene, or might prefer to avoid recalling the details of the traumatic event or a crime. These are the sustaining factors for crimerelated anxiety, fear and related symptoms. Victims can also report anger, and other self-conscious emotions such as shame and guilt; these are emotions that make a victim's disclosure of a traumatic event difficult. These emotions disrupt the processing of the traumatic event which is not a health way of coping with trauma. In addition, expectation of disapproval or disbelief from the social connections, which is seen particularly with victims of sexual assault, may exacerbate the symptomatology of PTSD (Zayfert \& Becker, 2019).

Treatment of PTSD by CBT has two core components; namely, exposure and cognitive restructuring. These two components aims to decrease avoidance behaviors. By graded exposure which could be either in real life or virtual reality, patients are equipped with an ability to make a distinction between cues of danger and cues of safety. Reprocessing of the traumatic event is also part of graded exposure. Exploration of thinking is promoted with an aim to process and understand the traumatic event better. Thoughts abut trauma are revisited and victim's conclusions of the traumatic event are critically examined.

There are other forms of CBT that draw attention in treatment of PTSD. One is stress inoculation therapy while the other is eye movement desensitization therapy (EMDR). The first form, stress inoculation therapy aims to teach a patient to manage stress effectively by some strategies like relaxation, thought stopping and assertive communication. While the other form; EMDR, aims to present a moving visual stimulus while revisiting the traumatic event. These processes are accompanied by cognitive restructuring to some degree (Zayfert \& Becker, 2019).

Another approach in psychological treatment of PTSD is metacognitive treatment which is in fact a kind of cognitive therapy (Wells, 2000). In this approach, the main aim is to deal with reflexive adaptation process (RAP). Wells and Sembi (2004a) points out that RAP is a normal reaction to immediate trauma and perseverance blocks RAP by 
metacognitions, i.e. cognitions about thinking style of oneself. Perseverations comprise of worry and rumination, threat monitoring, and dysfunctional though control mechanisms. Avoidance and dissociation further blocks emotional processing of trauma and give rise to perseveration. Depending on these premises, metacognitive therapy offers some ways to deal with perseverance including worry postponement, detached mindfulness, and attentional modification (Wells \& Sembi, 2004a). In another study, Wells and Sembi (2004b) applied metacognitive therapy to victims of various traumas such as armed robbery and they had promising results. The sample they worked with showed marked improvement in their PTSD symptoms. Their resuls were also effective in follow up measurements. Wells, Walton, Lovell, and Proctor (2015) conducted a study to compare the effectiveness of metacognitive therapy with prolonged exposure therapy in PTSD patients; they also had wait list group. In this current study, it is seen that both types of psychotherapy were effective in decreasing symptoms of PTSD, anxiety and depression when compared to wait-list group. The difference between metacognitive therapy with prolonged exposure therapy occurred in post-treatment measures (Wells et al., 2015).

Considering that there are many types of psychotherapy offering treatment to PTSD and each one of them have strengths in improvement of PTSD symptoms. At this point, one should focus on the studies investigating the parts of a therapy which make it more efficient. Therapeutic alliance, the relationship between a patient and a psychotherapist makes important and positive effects in treatment outcome and effectiveness studies. Having positive alliance, trust and genuineness in psychotherapist-patient dyad could make a therapy effective (Howgego, Yellowlees, Owen, Meldrum, \& Dark, 2003). In a study, sample consisted of people suffering from childhood abuse-related posttraumatic stress disorder (PTSD) and successful therapy outcomes were result of therapeutic alliance and emotional regulation capacity (Cloitre, Chase Stovall-McClough, Miranda, \& Chemtob, 2004).

\section{Professionals Working with Victims: Secondary Trauma, Vicarious Trauma, Compassion Fatigue, Countertransference and Occupational Burnout}

Once a devastating event occurs and people get affected from it whether directly or indirectly, many professionals begin working with this case to improve the consequences. Some of these professionals are ambulance drivers, the police, lawyers, search and rescue teams, paramedics, emergency department professionals such as physicians and nurses, psychologists, psychiatrists and social workers (Rothschild \& Rand, 2006; Y1lmaz \& Karakuş, 2019).
Studies show that professionals working closely with victims of devastating events are also traumatized in different ways such as trauma related stress and occupational burnout (Newell $\&$ MacNeil, 2010). Secondary traumatic stress and vicarious trauma are also observed in these professionals (Gürdil Birinci \& Erden, 2016). Because professionals working in humanitarian aid are engaging in interpersonal situations that have heavy emotional burden, they might have a specific kind of work-related stress which is called as "occupational burnout" (Leiter \& Maslach, 1988; Maslach \& Jackson, 1981).

Secondary traumatic stress refers to PTSD-related symptoms a person might have as a result of indirectly being exposed to trauma, this way of exposure occurs with working with survivors and/or victims with PTSD (Salston \& Figley, 2003). Vicarious traumatization is a more time dependent change in psychology of professionals working with victims (Gürdil Birinci \& Erden, 2016; Pearlman \& Saakvitne, 1995). Vicarious traumatization of professionals is a result of empathetic engagement with victims of trauma (Pearlman \& Saakvitne, 1995). Unlike secondary traumatic stress which is close to PTSD symptomatology with a sudden onset, vicarious trauma affects belief system of professionals and is not related to PTSD symptomatology (Pearlman \& Saakvitne, 1995). Belief about security, trust, dignity, intimacy and control are seriously affected in people forming interpersonal relationships with victims of devastating events (Pearlman \& Saakvitne, 1995). Compassion fatigue is another consequence that professionals working with victims might have. Compassion fatigue corresponds to feeling emotional and physical fatigue resulting from full appreciation of what a victim of a trauma experiences (Rothschild \& Rand, 2006; Salston \& Figley, 2003). Countertransference is yet another consequence a professional might have as a result of working with trauma victims (Salston \& Figley, 2003). Traumatic countertransference is defined as "...the spontaneous or evoked responses of the therapist in regard to information provided, behaviors exhibited, emotions displayed by the traumatized client." (Salston \& Figley, 2003, p.170). This type of countertransference retain psychotherapist in correctly diagnosing and treating trauma (Danieli, 1996).

Because of all these outcomes of working with victims of trauma, professionals, particularly mental health workers, should be offered alternative ways of treatment. They should be controlled on a regular basis to understand whether they have psychological consequences of working with victims. Group meetings, peer meetings, and supervision could offer professionals opportunities in sharing emotions, feelings, thoughts and behaviors related to their work.

\section{Discussion and Suggestions}

The aim of this study is to highlight a view from clinical psychology in discussing victimization. As a branch of psychology, 
psychological assessment, and diagnosis and treatment of psychological disorders and behavioral problems are main topics of clinical psychology (Plante, 2005). General victimology, as a multidisciplinary area, concerns victims of various types of traumas, from natural disasters to sexual assaults (Van Dijk, 1999). Clinical psychology addresses some common topics as victimization due to trauma with general victimology. Due to this intersection between clinical psychology and general victimization, the author discussed trauma related disorders, such as acute stress disorder, post-traumatic stress disorder, adjustment disorders, all of which are official diagnoses (APA, 2013). In addition to this, unofficial diagnoses reviewed in the literature were accounted. These unofficial diagnoses are battered woman syndrome (Walker, 1984), rape trauma syndrome (Burgess \& Holmstrom, 1974), and stalking trauma syndrome (Colins \& Wilkas, 2001). Brief history of official diagnoses of victims of trauma was included to better understand how these diagnoses showed up and how traumatic experiences seriously affect their victims. Moreover, psychological treatment of PTSD was explained since PTSD is a frequent consequence of victimization. Secondary trauma, vicarious trauma, compassion fatigue, countertransference and occupational burnout were included to appreciate how professionals working in victimization area are also seriously and psychologically affected from their work. These outcomes demonstrate that professionals are also affected negatively and for long time. Their beliefs and emotions about staying safe changed due to indirect exposure to victimization.

Nevertheless, traumatic experiences might lead people to develop a better meaning in life. People can overcome the difficulties embedded in victimization and can move to a better psychological state with the help of deriving some other meaning in life. Their coping mechanisms improve and they report positive change. People can switch from suffering from a traumatic event to forming supportive relationships, feeling more personal strength, and reporting enriched existential and spiritual life (Tedeschi \& Calhoun, 2004). Posttraumatic growth cannot be an excuse for victimization, but it is a consequence uncovering human potential to process and cope with suffering and trauma.

As a clinical psychologist, the author appreciates biopsychosocial model (Engel, 1977). This model offers to look for searching biological, psychological and social factors of a given outcome such as a traumatic event. Some people might have vulnerabilities to develop psychopathology and some others not, although they might experience the same event. These vulnerabilities might be biological or psychological. Psychological factors such as personality, social support and emotion regulation might protect a person from developing serious problems as a result of victimization. Social factors such as socioeconomic status and cultural norms might offer or hinder ways to a victim to recover from a traumatic event. All these factors are intertwined and constantly affecting each other. In terms of victimization, all these factors are better be investigated for victims, perpetrators, and for the context that the devastating event occurred. In other words, trauma is a serious event and its effects are long-lasting; hence, to fully understand it, factors surrounding the traumatic event should be analyzed altogether.

Mental health workers including clinical psychologists should be better equipped to engage in their work with victims and to feel well in performing their job. Training of mental health workers should include strategies to understand, empathize, connect with and treat victims of traumatic events. These strategies could include discussing real-life examples, hypothetical cases, and examples shown in various types of media. Books, movies, series, documentaries, and records of real-life examples are valuable sources of training. The author might suggest some media for fulfill as aim.

For instance, The Sinner, an American drama series is a perfect example of victimization, criminal justice and psychological interviewing and treatment of victims (Y1lmaz, 2019b). Another source is the book, The boy who was raised as a dog, by Perry and Szalavitz (2017) to better understand the situation of child victims. How children's brain development is affected due to perpetual traumatic family interactions is explained in this book.

Authors' Contributions The author prepared all the manuscript.

Funding This study received no specific grant from any funding agency in the public, commercial, or not-for-profit sectors.

Data Availability Not available.

Code Availability Not Applicable

\section{Declarations}

Ethics Approval Not available.

Consent to Participate Not available.

Consent for Publication The author gives consent for publication in Current Psychology Journal.

Informed Consent This study is a review study; no data were gathered so informed consent was not necessary.

Conflict of Interest The Author declares no conflict of interest.

\section{References}

Altınay, A. G., \& Arat, Y. (2007). Türkiye’de Kadına Yönelik Şiddet Araştırma Raporu. Tübitak: Ankara.

American Psychiatric Association. (2013). Diagnostic and statistical manual of mental disorders (5th ed.). Washington, DC: Publisher. 
Andreasen, N. C. (2004). PTSD as defined by the MD who wrote the dedinition DSM 11l. American Journal of Psychiatry, 161, 13211323.

Bachem, R., \& Maercker, A. (2016). Self-help interventions for adjustment disorder problems: A randomized waiting-list controlled study in a sample of burglary victims. Cognitive behaviour therapy, 45(5), 397-413. https://doi.org/10.1080/16506073.2016.1191083.

Benedict, R. H. B. (1989). The effectiveness of cognitive remediation strategies for victims of traumatic head-injury: A review of the literature. Clinical Psychology Review, 9(5), 605-626.

Blanchard, E. B., Hickling, E. J., Vollmer, A. J., Loos, W. R., Buckley, T. C., \& Jaccard, J. (1995). Short-term follow-up of post-traumatic stress symptoms in motor vehicle accident victims. Behaviour Research and Therapy, 33(4), 369-377.

Bracha, H. S. (2004). Freeze, flight, fight, fright, faint: Adaptationist perspectives on the acute stress response spectrum. CNS Spectrums, 9(9), 679-685.

Burgess, A., \& Holmstrom, L. (1974). Rape trauma syndrome. American Journal of Psychiatry, 131(9), 981-986.

Butcher, J. N., Hooley, J. M., \& Mineka, S. (2014). Abnormal psychology (16th ed.). Upper Saddle River, NJ: Pearson.

Campfield, D. C. (2008). Cyber bullying and victimization: Psychosocial characteristics of bullies, victims, and bully/victims. (Unpublished doctorate disseration). University of Montana, Missoula, USA

Cloitre, M., Chase Stovall-McClough, K., Miranda, R., \& Chemtob, C. M. (2004). Therapeutic alliance, negative mood regulation, and treatment outcome in child abuse-related posttraumatic stress disorder. Journal of Consulting and Clinical Psychology, 72(3), 411416.

Colins, M. J., \& Wilkas, M. B. (2001). Stalking trauma syndrome. In J. A. Davis (Ed.), Stalking crimes and victim protection (pp. 317-334). Boca Raton: CRC Press.

Danieli, Y. (1996). Who takes care of the caregiver? In R. J. Apfel \& B. Simon (Eds.), Minefields in their hearts (pp. 189-205). New Haven: Yale University Press.

Engel, G. L. (1977). The need for a new medical model: A challenge for biomedicine. Science, 196(4286), 129-136.

Foa, E. B., Rothbaum, B. O., Riggs, D. S., \& Murdock, T. B. (1991). Treatment of posttraumatic stress disorder in rape victims: A comparison between cognitive-behavioral procedures and counseling. Journal of Consulting and Clinical Psychology, 59(5), 715-723.

Frommberger, U., Stieglitz, R. D., Straub, S., Nyberg, E., Schlickewei, W., Kuner, E., \& Berger, M. (1999). The concept of "sense of coherence" and the development of posttraumatic stress disorder in traffic accident victims. Journal of Psychosomatic Research, 46(4), 343-348.

Gürdil Birinci, G., \& Erden, G. (2016). Yardım çalışanlarında üstlenilmis travma, ikincil travmatik stres ve tükenmişliğin değerlendirilmesi. Türk Psikoloji Dergisi, 31(77), 10-26.

Hensel-Dittmann, D., Schauer, M., Ruf, M., Catani, C., Odenwald, M., Elbert, T., \& Neuner, F. (2011). Treatment of traumatized victims of war and torture: A randomized controlled comparison of narrative exposure therapy and stress inoculation training. Psychotherapy and Psychosomatics, 80(6), 345-352.

Howgego, I. M., Yellowlees, P., Owen, C., Meldrum, L., \& Dark, F. (2003). The therapeutic alliance: The key to effective patient outcome? A descriptive review of the evidence in community mental health case management. Australian and New Zealand Journal of Psychiatry, 37(2), 169-183.

Karmen, A. (2012). Crime victims: An introduction to Victimology (eighth ed.). Toronto: Wadsworth New York.

Keane, T. M., \& Barlow, D. H. (2002). Posttraumatic stress disorder. In D. H. Barlow (Ed.), Anxiety and its disorders (2nd ed.) (pp. 418453). New York: Guilford Press

Kilpatrick, D. G., Saunders, B. E., Veronen, L. J., Best, C. L., \& Von, J. M. (1987). Criminal victimization: Lifetime prevalence, reporting to police, and psychological impact. Crime \& Delinquency, 33(4), 479-489.

Kimerling, R., \& Calhoun, K. S. (1994). Somatic symptoms, social support, and treatment seeking among sexual assault victims. Journal of Consulting and Clinical Psychology, 62(2), 333-340.

Leiter, M. P., \& Maslach, C. (1988). The impact of interpersonal environment on burnout and organizational commitment. Journal of Organizational Behavior, 9(4), 297-308. https://doi.org/10.1002/ job.4030090402.

Lorenz, L., Bachem, R. C., \& Maercker, A. (2016). The adjustment disorder-new module 20 as a screening instrument: Cluster analysis and cut-off values. Int Journal of Occupational and Environmental Medicine (The IJOEM), 7(4), 775-215.

Lönnqvist, J. K., Henriksson, M. M., Sisometsä, E. T., Marttunen, M. J., Heikkinen, M. E., Aro, H. M., \& Kuoppasalmı, K. L. (1995). Mental disorders and suicide prevention. Psychiatry and Clinical Neurosciences, 49, S111-S116.

Maslach, C., \& Jackson, S. E. (1981). The measurement of experienced burnout. Journal of Organizational Behavior, 2(2), 99-113. https:// doi.org/10.1002/job.4030020205.

Mason, F., \& Lodrick, Z. (2013). Psychological consequences of sexual assault. Best Practice \& Research Clinical Obstetrics \& Gynaecology, 27(1), 27-37.

Newell, J. M., \& MacNeil, G. A. (2010). Professional burnout, vicarious trauma, secondary traumatic stress, and compassion fatigue: A review of theoretical terms, risk factors, and preventive methods for clinicians and researchers. Best Practices in Mental Health, 6(2), $57-67$.

Nishith, P., Resick, P. A., \& Griffin, M. G. (2002). Pattern of change in prolonged exposure and cognitive-processing therapy for female rape victims with posttraumatic stress disorder. Journal of Consulting and Clinical Psychology, 70(4), 880-886.

Öztürk, E. (2020). Travma ve dissosiyasyon psikotravmatoloji tanı kitabı: Dissosiyatif kimlik bozukluğunun psikoterapisi ve aile dinamikleri. İstanbul: Nobel Tip.

Pearlman, L., \& Saakvitne, K. (1995). Trauma and the therapist: countertransference and vicarious traumatization in psychotherapy with incest survivors. American Journal of Clinical Hypnosis, 4, 451. https://doi.org/10.1080/00029157.1996.10403354.

Perry, B. D., \& Szalavitz, M. (2017). Köpek Gibi Büyütülmüş Çocuk [the boy who was raised as a dog: And other stories from a child Psychiatrist's notebook - what traumatized children can teach us about loss, love, and healing] (Turkish version translated by B. S. Haktanir). İstanbul: Koridor Press.

Plante, T. G. (2005). Contemporary clinical psychology. New Jersey: Johyn Wiley \& Sons.

Resick, P. A., \& Schnicke, M. K. (1992). Cognitive processing therapy for sexual assault victims. Journal of Consulting and Clinical Psychology, 60(5), 748-756.

Resick, P. A., Nishith, P., Weaver, T. L., Astin, M. C., \& Feuer, C. A. (2002). A comparison of cognitive-processing therapy with prolonged exposure and a waiting condition for the treatment of chronic posttraumatic stress disorder in female rape victims. Journal of Consulting and Clinical Psychology, 70(4), 867-879.

Rothschild, B., \& Rand, M. (2006). Help for the helper, self-care strategies for managing burnout and stress: The psychophysiology of compassion fatigue and vicarious trauma. New York: W. W. Norton.

Rubonis, A. V., \& Bickman, L. (1991). A test of the consensus and distinctiveness attribution principles in victims of disaster 1 . Journal of Applied Social Psychology, 21(10), 791-809.

Rüstemli, A., \& Karanci, A. N. (1999). Correlates of earthquake cognitions and preparedness behavior in a victimized population. The Journal of Social Psychology, 139(1), 91-101. 
Salston, M., \& Figley, C. R. (2003). Secondary traumatic stress effects of working with survivors of criminal victimization. Journal of Traumatic Stress, 16(2), 167-174.

Schultz, D., \& Schultz, S. (2008). A history of modern psychology (9th. ed.). Upper Saddle River: Wadsworth Cengage Learning.

Shalev, A. Y. (2009). Posttraumatic stress disorder and stress-related disorders. Psychiatric Clinics, 32(3), 687-704.

Sirles, E. A., Smith, J. A., \& Kusama, H. (1989). Psychiatric status of intrafamilial child sexual abuse victims. Journal of the American Academy of Child \& Adolescent Psychiatry, 28(2), 225-229.

Sumer, N., Karanci, A. N., Berument, S. K., \& Gunes, H. (2005). Personal resources, coping self-efficacy, and quake exposure as predictors of psychological distress following the 1999 earthquake in Turkey. Journal of Traumatic Stress: Official Publication of The International Society for Traumatic Stress Studies, 18(4), 331-342.

Tedeschi, R. G., \& Calhoun, L. (2004). Posttraumatic growth: A new perspective on psychotraumatology. Psychiatric Times, 21(4), 5860.

Turvey, B. E. (2014). Forensic victimology: Examining violent crimes in investigating and legal contexts. Waltham: Elsevier.

van Dijk, J. J. M. (1999). Introducing victimology. In J. J. M. van Dijk, R. G. H. van Kaam, \& J. Wemmers (Eds.), Caring for crime victims: Selected proceedings of the Ninth International Symposium on Victimology, Amsterdam, August 25-29, 1997 (pp. 1-12). Criminal Justice Press.

Walker, L. E. (1984). The battered woman syndrome. New York: Springer.

Wells, A. (2000). Emotional disorders and metacognition: Innovative cognitive therapy. Chichester: Wiley.
Wells, A., \& Sembi, S. (2004a). Metacognitive therapy for PTSD: A core treatment manual. Cognitive and Behavioral Practice, 11(4), 365377.

Wells, A., \& Sembi, S. (2004b). Metacognitive therapy for PTSD: A preliminary investigation of a new brief treatment. Journal of Behavior Therapy and Experimental Psychiatry, 35(4), 307-318.

Wells, A., Walton, D., Lovell, K., \& Proctor, D. (2015). Metacognitive therapy versus prolonged exposure in adults with chronic posttraumatic stress disorder: A parallel randomized controlled trial. Cognitive Therapy and Research, 39(1), 70-80.

Wolynn, M. (2017). It didn't start with you: How inherited family trauma shapes who we are and how to end the cycle. USA: Penguin.

Yılmaz, T., \& Karakuș, C. (2019). Klinik Psikoloji Bağlamında Kadına Yönelik Aile İçi Şiddetin Değerlendirilmesi: Kadın, Çocuk ve Meslek Elemanlarının Psikolojisi Üzerine Bir Gözden Geçirme Çalıșması. Mediterranean Journal of Humanities, 19(2), 573-588.

Yılmaz, T. (2019a). Ruhsal Bozuklukların Tanısal ve Sayımsal El Kitabının (DSM) Son İki Baskısı Arasındaki Değișikliklerin İncelenmesi. In T. Yılmaz (Ed.), Psikoloji, Sosyoloji ve Coğrafya Bakış Açısından Sağlık (pp. 1-19). Ankara: Berikan.

Yılmaz, T. (2019b). The sinner dizisinin travma sonrası stres bozukluğu bağlamında çözümlemesi (analysis of the sinner series in terms of post traumatic stress disorder). AYNA Clinical Psychology Journal, 6(2), 183-203.

Zara-Page, A., \& İnce, M. (2008). Aile İçi Şiddet Konusunda Bir Derleme. Türk Psikoloji Yazıları, 11(22), 81-94.

Zayfert, C., \& Becker, C. B. (2019). Cognitive-behavioral therapy for PTSD: A case formulation approach. New York: Guilford Press.

Publisher's Note Springer Nature remains neutral with regard to jurisdictional claims in published maps and institutional affiliations. 